\title{
O PSICODRAMA EM SALA DE AULA: UMA ESTRATÉGIA DE ENSINO PARA O DESENVOLVIMENTO DO PAPEL PROFISSIONAL DA ENFERMEIRA*
}

\author{
Débora I. R. Kirschbaum** \\ Márcia Regina Nozawa **
}

\begin{abstract}
RESUMO: Examinam-se os principais conceitos do método psicodramático e as possibilidades de utilização deste na educação de enfermeiras, através do emprego de técnicas psicodramáticas, particularmente o "role-playing" em sala de aula, com o objetivo de desenvolver relações interpessoais e papéis sociais, por meio da educação da espontaneidade. São relatadas duas situações em que foi empregada esta técnica na disciplina "Integração do Estudante de Engermagem à Profissão", dirigida a alunos do $1^{\circ}$ ano do Curso de Graduação em Enfermagem da UNICAMP. Verifica-se que sua utilização propicia ao aluno vivenciar os três diferentes momentos que constituem o jogo de papéis: o "role-taking", o "role-playing" e o "role-creating".
\end{abstract}

\begin{abstract}
The author looks into the main concepts of the psico-dramatic method and its the possibility of its use in educating nurses, particularly the "role-playing" in the classroom, aiming at developing interpersonal relationship and social roles, by means of a sponteneous education. Two situations are described, in which this method was employed in a "Getting the Student Acquainted with the Nursing Profession" class, for freshmen in the Graduate Course of UNICAMP. It is verified that the method provides the student with virtual experience for the three different stages of the "role-taking", the "role-playing" and the "role-creating".
\end{abstract}

\section{INTRODUÇÃO}

Criado por Jacob L. MORENO, na primeira metade do século XX, o psicodrama constitui uma proposta de arte, teatro, ciência, psicoterapia e educação. Um método de trabalho que emprega técnicas psicodramáticas, visando o estudo e a transformação das relações interpessoais dos grupos e da sociedade na qual estão inseridos. Sua origem é o teatro, de onde provém a concepção de drama, da qual foram extraídos os conceitos que fundamentam a teoria e a prática psicodramática $^{(1)}$ Foi a partir da observação e do estudo dos elementos emergentes nas dramatizações que MORENO***, elaborou os conceitos de espontaneidade, criatividade e conserva cultural, que servem de base a socionomia, a qual ele define como "o estudo das leis do desenvolvimento social e das relações sociais". Tais conceitos são compreendidos conjuntamente, constituindo a Teoria da Espontaneidade.

A espontaneidade é definida como a capacidade do indivíduo de dar soluções originais e adequadas a situações novas, ou de responder de forma nova a situações antigas. Neste sentido, constitui uma condição do sujeito que lhe possibilitaria agir livremente $\mathrm{e}$ como tal, esta não está dada, mas precisa ser educada, ou melhor, adquirida por meio de preparação do indivíduo para exercer sua ação livremente. Se a espontaneidade é uma qualidade, a criatividade é a sua substância, é ela o elemento que possibilita a produção de um novo modo de agir. O produto "final" deste processo criador é a Conserva Cultural, que por sua

* Trabalho apresentado como tema livre no $44^{\circ}$ Congresso Brasileiro de Enfermagem., Brasilia. D.F., 4 a 9 de outubro de 1992.

** Prof essoras Assistentes do Departamento de Enfermagem, Área de Enfermagem em Saúde Pública e em Saúde Mental, da FCM/UNICAMP.

*** Moreno, J.L. Sociometry, experimental method and the science of society. Apud KAUFMANN, Arthur. O teatro pedagógico, p.57. 
vez, é a responsável pela preservação da cultura e pela transmissão do "status quo" às novas gerações. Mas. quando tomada como algo estático, ela inviabiliza a emergência da espontaneidade.

Além desta, a Teoria dos Papéis também nos fala sobre o desenvolvimento das relações entre o indivíduo e o grupo. Para MORENO, o EU emerge dos papéis e estes são aprendidos ao longo da história individual, em função de diferentes vínculo estabelecidos entre o indivíduo e os grupos com os quais se relaciona. Nesse sentido, o grupo é uma rede de relações de papéis, que possuem três diferentes categorias: os papéis psicossomáticos, os sociais e os psicodramáticos.*

O Teatro da Espontaneidade, que foi a forma inicial assumida pelo Psicodrama, prescinde de textos prontos e de papéis definidos. Ao contrário disto, propõe a dramatização espontânea de um texto, cujo autor é o próprio protagonista, emergente do grupo, a partir do qual estabelecem-se os papéis dos demais atores, sendo o espetáculo coordenado por um diretor, auxiliado por uma equipe técnica: os ego-auxiliares. Ele pode ter como objetivo imediato o espetáculo, ou um sentido terapêutico, mas constitui também um método de ensino, que propicia aos atores que dele participam, entrarem em contato com papéis que representam em sua vida diária, ou que irão representar, no caso dos estudantes em processo de formação profissional.

O método psicodramático dispõe de várias técnicas, dentre os quais o "role-playing" que discutiremos a seguir.** Segundo ALMEIDA(2), este desenvolve-se em três níveis operacionais: o "role-taking", o "role- playing" propriamente dito, e o "role-creating". O primeiro implica em tomada ou aceitação do papel, na qual o indivíduo adota um papel socialmente constituído, sem incorporar ao mesmo, muitas características pessoais. O "role-playing", que consiste no jogo, ou desempenho, ou interpretação de papéis, implica na tomada de um papel social com certo grau de liberdade, e incorporação de características pessoais e da subjetividade do ator. Ao passo que, o "role-creating", consiste na criação do papel, quando o indivíduo assume um papel social e converte-o em psico-dramático. Em todos eles, procura-se aproxi- mar a interpretação do papel aos aspectos da vida diária do ator, a situações, portanto, que lhe digam respeito.

O "role-playing" tem sido amplamente utilizado no campo da educação, justamente pelas possibilidades que oferece ao desenvolvimento da espontaneidade, fundamental para a identificação e a aquisição do papel profissional. $* * *$

\section{OBJETIVOS}

A introdução do psicodrama como estratégia pedagógica, tem por objetivo propiciar ao aluno de enfermagem a obtenção de um estado de espontancidade, que the possibilite desempenhar adequadamente seus papéis sociais de aluno e de enfermeiro.

\section{METODOLOGIA}

A população atendida foi constituída de alunos do $1^{\circ}$ ano do Curso de Graduação em Enfermagem da FCM/UNICAMP, tendo sido utilizada a técnica Teatro da Espontaneidade - "role-playing".

\section{APRESENTAÇÃO DA EXPERIÊNCIA}

A idéia de utilizar o psicodrama em aulas de diferentes disciplinas do curso de Graduação em Enfermagem da UNICAMP, of erecidas pelas Área de Enfermagem em Saúde Pública e em Saúde Mental, decorreu da necessidade de utilizar métodos de ensino que possibilitassem romper com a dissociação entre teoria e prática, entre emoção e razão, tendência muito frequientemente expressa nas atitudes e no discurso dos estudantes com os quais trabalhamos no primeiro ano do curso. Na respectiva disciplina, Integração do Estudante à Profissão, busca-se propiciar ao aluno, o desenvolvimento de seu papel profissional, e ampliar sua percepção quanto a "estar em relação com o outro", assim como, aprimorar as relações interpessoais no próprio grupo de alunos, o que consideramos a base para a produção de todo trabalho coletivo, no caso, a própria formação dos alunos.

Neste sentido, a utilização do Teatro da Espontaneidade, particularmente da técnica de "roleplaying", ocorre em diferentes oportunidades, de-

\footnotetext{
* Cf. KAUFMANN, A., op. cit., p.67, sobre as categorias de papéis.

** Sobre as técnicas psicodramáticas, consultar AGUIAR, Moysés. Teatro da anarquia, um resgate do psicodrama; KAUFMANN, A. op. cit., e ALMEIDA, Wilson C. A pedagogia do ato criador.

*** Cf. ALMEIDA, Wilson, op. cit., p.1-11 e KAUFMANN, Arthur, op. cit., p. 75-79.
} 
pendendo do que se pretende trabalhar e das necessidades do grupo de alunos percebidas pelos professores. Enfocaremos aqui duas situações em que o "roleplaying" foi utilizado para trabalhar o conceito de enfermeiro, enquanto papel profissional, e para desenvolver habilidades no relacionamento interpessoal entre docentes e discentes. com vistas a obter uma maior espontaneidade no desenvolvimento do trabalho acadêmico.

Na primeira situação, com alunos do $1^{\circ}$ ano, no primeiro dia de aula, realizamos um jogo dramático, com a finalidade de propiciar o aquecimento grupal, que consistia em jogar uma bola de barbante para cada participante, que ao recebê-la, se auto-apresentava e devolvia-a a outro elemento do gnupo, cuidando de manter consigo um pedaço do barbante. Ao final, forma-se uma teia, que foi interpretada pelo grupo como um símbolo da união da turma. A partir disto, montamos a dramatização, escolhendo o protagonista, que ao emergir do grupo, trouxe como tema a "enfermeira recém-formada", trabalhando em situações de emergência num centro-cirúrgico. Na cena, as alunas mantiveram-se na etapa de "role-taking", representando papéis de forma convencional, nos quais emergiam os "mitos" da enfermagem; as situações conflitivas entre médicos, enfermeiras e ocupacionais de enfermagem, que imaginavam os alunos, caracterizavam o cotidiano da enfermeira; a desvalorização social do papel da enfermeira, dentre outras questões, que foram levantadas na etapa do compartilhamento, que sucede à dramatização. Uma delas foi a sensação de "estar perdido", tanto em relação ao que fosse a profissão enfermeira, quanto em relação ao que lhes reservava a vida universitária, que iniciavam naquele momento. Três meses depois, após um estágio de observação do cotidiano e do trabalho de enfermeiras em diferentes serviços de saúde, foi realizada uma nova dramatização, cuja finalidade era identificar a mudança na visão que as alunas possuíam da atividade da enfermeira. Fez-se o aquecimento com o objetivo de identificar a protagonista e esta trouxe como cena o trabalho de uma enfermeira psiquiátrica, realizando um grupo terapêutico com pacientes drogaditos, situação que, aliás não havia sido experimentada no estágio de observação, situando-se claramente nas etapas de "role-playing" e "role-creating".

\section{CONSIDERAÇÕES FINAIS}

A experiência aqui relatada visa apontar as possibilidades do psicodrama, particularmente do Teatro da Espontaneidade e do "role-playing", como técnicas de eleição na educação em enfermagem. Tais técnicas possibilitam ao estudante desenvolver papéis sociais e relações inter pessoais num ambiente relaxado e protegido, onde este experimenta diferentes graus de espontaneidade, vivenciando o processo de tomada, interpretação e criação do papel profissional da enfermeira.

\section{REFERÊNCIAS BIBLIOGRÁFICAS}

1. AGUIAR, Moysés. Teatro da anarquia: um resgate do psicodrama. Campinas: Papirus, 1988.

2. ALMEIDA, Wilson C. A pedagogia do ato criador. In: CONGRESSO BRASILEIRO DE PSICODRAMA, VI, Salvador, 1988. Texto apresentado na Mesa Redonda "Metodologia do Psicodrama". (mimeo)
3. KAUFMANN, Arthur. O teatro pedagógico: bastidores da iniciação médica. São Paulo: Ágora, 1992.

Recebido para publicação em 23.08.93 